Title:

Author:

Affiliation:

Correspondence Address: Department of Educational Research

Lancaster University

Lancaster

UK

LA14YL

Email: p.ashwin@lancaster.ac.uk 


\title{
Variation in Academics' Accounts of Tutorials
}

\begin{abstract}
There is a growing literature that has examined academics' approaches to, and accounts of, teaching. One aspect that has not been examined is academics' perceptions of particular teaching methods. In this study, academics' accounts of tutorials at the University of Oxford were used as an 'ideal type' in order to examine whether there is variation in the ways that academics experience a single teaching method. An analysis of interviews with 20 academics constituted four qualitatively different ways in which academics described the purpose of tutorials. This paper examines whether there appeared to be systematic subject-based differences in the ways academics' described tutorials, as well as examining relations between academics' accounts of tutorials and their approaches to teaching. In doing so, the study offers insight into the different ways in which academics account for a particular teaching and learning task, which has important implications for the approach that is taken to supporting university teaching more generally
\end{abstract}

Key Words: Tutorials; Academics; Phenomenography; Approaches to Teaching; Teaching Methods 


\section{Variation in Academics' Accounts of Tutorials}

\section{Introduction}

There has been a growing literature over the past fifteen years or so that has examined university academics' approaches to, and conceptions, of teaching (for example Martin \& Balla 1991, Samuelowicz \& Bain 1992, Gow \& Kember 1993, Trigwell \& Prosser 1996). Akkerlind (2003) summarises this research and argues that from a range of research perspectives these studies have consistently suggested that a key variation in the ways in which academics approach and conceptualise their teaching is whether they are focused on their teaching and how they transfer information to students (an information transfer/ teacher focused approach to teaching) or whether they are focused on their students' learning and how their students develop their conceptual understanding (a conceptual change/ student focused approach to teaching).

Academics' approaches to teaching have also been found to relate to students' approaches to learning. The students of academics who report adopting an information transfer/teacher focused approach to teaching are more likely to adopt an approach to learning focused on the reproduction of information (a surface approach to learning), whereas the students of academics who report adopting a conceptual change/student focused approach to teaching are more likely to adopt an approach to learning focused on developing a personal understanding of the course material (a deep approach to learning) (Gow and Kember 1993, Trigwell et al 1999, Prosser \& Trigwell 1999). This is significant because students who adopt a deep approach tend to achieve higher quality learning outcomes than students who adopt a surface 
approach to learning (Prosser \& Trigwell 1999). Thus there appears to be a relation between the ways in which academics' approach their teaching and the quality of students' learning outcomes.

An important aspect of much of this research is that academics' approaches to teaching are relational (Prosser \& Trigwell 1999, Åkerlind 2003), thus, rather than being a relatively stable characteristic of an academic, they change according to academics' perceptions of their situation. Prosser \& Trigwell's (1997) findings suggest that where academics perceive that they have control over what is taught and how it is taught; they perceive that the class size is not too large; and they perceive that their department values teaching; they are more likely to adopt a conceptual change/student focused approach to teaching.

One related aspect of academics' perceptions of their teaching situation that has not been examined is their perception of particular teaching methods, such as lectures, seminars and tutorials. The research reported in this paper sought to address this issue through an examination of academics' accounts of tutorials and relating these to academics' approaches to teaching more broadly. In this way, the study sought to examine whether there is anything intrinsic in a particular method of teaching that leads academics to think about it in a conceptual change/student focused or a information transfer/teacher focused way, or whether the variation that has been constituted in relation to academics' conceptions of teaching could also be constituted in relation to a particular teaching method. This was investigated because whether or not there is variation in the ways in which academics experience a particular 
teaching method has important implications for the ways in which academics are supported in developing their teaching.

\section{Tutorials at the University of Oxford}

This study focused on academics' experiences of tutorials at the University of Oxford and sought to use this as a way of examining academics' accounts of a particular teaching method. Tutorials at the University of Oxford are part of a learning system that usually involves students in a period of intensive individual study, the preparation of some work, whether an essay or completion of a problem sheet, followed by the tutorial itself. Students usually have about 3 tutorials a fortnight and report spending about 13 hours preparing for each tutorial (Commission of Inquiry 1997).

Whilst it might be argued that this is such an unusual teaching and learning environment as to be of interest only to those within Oxford, this study sought to use it as an 'ideal type' in two senses of the phrase. First, it sought to use it as an 'ideal type' in the sense of an atypical case that could be used to illuminate aspects of academics' experiences of teaching methods more generally. As Trowler and Turner (2002) argue, there is a long tradition in the social sciences of drawing on the heuristic power of the atypical in order to illuminate more common situations. Second, it sought to use it as an 'ideal type' in the sense that tutorials at the University of Oxford can be argued to provide an ideal teaching environment. This is because the tutorial system has the three features that, Prosser \& Trigwell (1997) argued, provide a teaching context that is supportive of a conceptual change/student focused 
approach to teaching i.e. class sizes that are not too large, academics having control over their teaching, and teaching that is valued by the institution.

First, tutorials at Oxford tend to be relatively small in size with one tutor working with between one and six students (Commission of Inquiry 1997). The Commission of Inquiry (1997) found that the most common size of tutorial was 2 students but that tutorials in social sciences, sciences and engineering tended to be bigger than those in the arts.

Second, tutors have autonomy in deciding how to structure, and what content to focus on, in tutorials (Commission of Inquiry 1997), although a general structure appears to be that there will be an interrogation, whether questioning or discussion, of the work that the students have completed in preparation for the tutorial (UGC 1964, Moore 1968, Commission of Inquiry 1997, Tapper \& Palfreyman 2000, Palfreyman 2001). This work may be handed in beforehand, in the case of an essay it may be read out in the tutorial, or the tutor may take in the work at the end of the tutorial or not at all. The discussion usually starts with the students being given the opportunity to ask any questions they have about the subject matter and, proceeds from there.

Finally, tutorial teaching is highly valued within the institution. Tapper \& Palfreyman (2000 p.96), for example, refer to the tutorial system as the 'jewel in the crown', whilst Palfreyman's (2001) edited collection offers many accounts of the effectiveness of the tutorial system. For example, Shale (2001), in her contribution to this collection, argues that 
tutorials at Oxford are student-focused, as they focus on the student developing their understanding of their both their discipline and of the demands of higher learning:

\footnotetext{
"One of the great strengths of the tutorial system [at Oxford] is that it enables tutors and students to engage in dialogue that demands more sophisticated levels of understanding, and suggests new conceptions of learning. Tutorial teaching encourages students to make the discovery that higher learning is different from, and demands more of them, than learning as they may previously conceived of it" (Shale 2001, p.98)
}

This study sought to examine whether these apparently highly supportive conditions for teaching resulted in tutors approaching their teaching in a consistently conceptual change/student focused way or whether variation existed in tutors' accounts of tutorials and, if so, what factors appeared to be related to variation in these accounts. Although a previous study had examined students' conceptions of tutorials at Oxford (Ashwin 2005), and there are commentaries on the purposes of these tutorials (for examples see UGC 1964, Moore 1968, Tapper \& Palfreyman 2000, Palfreyman 2001), there is no previous research which examines the qualitative variation in academics' accounts of tutorials at Oxford, or tutorials more generally.

\section{Method}

A phenomenographic approach was taken in conducting this research. This is because this research sought to examine the variation in the ways that a group of academics experienced tutorials. As Marton \& Booth (1997, p.111) argue, "At the root of phenomenography lies an 
interest in describing the phenomena in the world as others see them, and in revealing and describing the variation therein, especially in an educational context".

Twenty tutors (T1 to T20) of undergraduate students were interviewed about their experience of tutorials at Oxford. In line with other phenomenographic studies (see Åkerlind 2005), the tutors were selected to maximise the potential variation in academics' experiences of tutorials in terms of discipline, length of tutoring experience and gender rather than to provide a representative sample of academics involved with tutoring at Oxford. Two disciplines were selected from each of the University's five divisions (Humanities, Life and Environmental Sciences, Mathematical and Physical Sciences, Medical Sciences, and Social Sciences) and two tutors were selected from each of the disciplines. Those interviewed were selected to maximise the variation in experience of tutoring at Oxford. This ranged from 2 years to 40 years experience. Seven of the academics had less than 10 years experience of tutoring at Oxford, six had between 10 and 19 years experience, and seven had greater than 20 years experience. The average length of experience of tutoring was 16.3 years. Eleven of the tutors interviewed were men and nine were women.

In the interviews, academics were first asked about their experience of running tutorials generally, and then asked to describe a particular undergraduate tutorial they had given, from any preparation work they had set students through to the tutorial itself. The interviews were then structured around this description, with particular attention paid to what the tutor saw as the purpose of this particular tutorial and how they understood their role, as well as the role of student(s), within this tutorial. 
The interviews were analysed using a phenomenographic approach (Marton \& Booth 1997). The focus was on qualitative variation in the ways in which the tutors experienced tutorials at Oxford. Categories of description of 'ways of describing tutorials' were formed by examining the qualitative variation in meaning in tutors' accounts of tutorials and the logical relations between the categories of description. The categories were formed and reformed by moving between these two forms of examination with the aim of constituting a hierarchy of empirically grounded and logically consistent categories of description of the different ways in which tutors described tutorials. The analysis was carried out by the author, with a colleague who verified that the categories of description could be justified on the basis of transcripts of the interviews.

A number of things should be noted about the approach to phenomenography adopted in this study. First, it should also be noted that the outcomes from phenomenographic studies are based on the variation across all of the interview transcripts rather than a categorisation of each individual in the study. Thus any one interview may contain more than one of the categories of description constituted in this study.

Second, it should also be noted that the claim being made about the outcome space is that it is constituted in the relation between the researcher and the data (Marton \& Booth 1997). Thus, it is accepted that it is not the only possible outcome that could be constituted from the data. What is important is that the categories can be argued for convincingly on the basis of the data (see Åkerlind 2005 for an analysis of the different approaches taken in 
phenomenographic studies). In line with other phenomenographic studies the outcomes in this study were critically examined by an experienced researcher in the field who checked that the construction of the categories was supported by the transcripts. Quotations are also provided under the description of each category in the 'Results' section, to allow readers to examine, to a limited extent given the limitations of space, how the transcripts supported the categories. However, it should also be noted that it is the variation between the categories, rather than the categories themselves, that are the focus in phenomenography and thus it is the differences between the quotes in the different sections that should be examined and questioned.

Third, as this element of the study is based solely on interview data, it is probably more accurate to describe what is constituted as tutors' accounts of tutorials rather than, as is more common in phenomenographic research, tutors' conceptions (see Richardson 1997, Säljö 1997 for a fuller discussion of this). However, as McCune (2004, p.261) argues in relation to student interviews, if there is evidence that interview analyses can be "related in meaningful ways to the outcomes of students' learning", this provides evidence that interviewees' accounts are related to their practice. The Approaches to Teaching Inventory (ATI) (Prosser \& Trigwell 1999) was used in this study because academics' accounts of their approaches to teaching have been found to relate to measures of the quality of students' learning (Trigwell et al 1999, Trigwell \& Prosser 1999), and thus can provide a link between academics' accounts of their teaching and their teaching practice. 
The academics were asked to complete the ATI, at the end of the interview, in relation to the same course that was the focus of the tutorial they had described in the interview. Eighteen of the twenty tutors agreed to complete a copy of the ATI, which contains two scales. The Information Transmission/Teacher-focused approach (ITTF) scale measures the degree to which teachers self report adopting an approach to teaching that focuses on the information that they seek to transfer as teachers. The Conceptual Change/Student-focused approach (CCSF) scale measures the degree to which teachers self report focusing on student learning as the focus of their activities. Tutors' scores on each of these scales were related to the highest category of ways of describing tutorials that they expressed in their interview. In doing so, this part of the study moves away from a purely phenomenographic approach because the focus on variation across all of the interview transcripts is replaced by a focus on how the responses of individual tutors can be categorized. As indicated above, this compromise was made in order to allow a link to be made between tutors' accounts of tutorials and their teaching practice. Similar compromises were made in comparing tutors' accounts of tutorials with their disciplines, their gender, their levels of experience and their perceptions of the teaching and learning environment.

\section{Results}

Four qualitatively different ways of describing tutorials were constituted in the analysis of the interviews:

1. Tutorials as a place where tutors help students to develop an understanding of concepts; 
2. Tutorials as a place where students see how to approach their discipline;

3. Tutorials as a place where evidence is critically discussed;

4. Tutorials as a place where new positions on the topic are developed and refined.

The qualitatively different descriptions of the tutorial were constituted by different tutor descriptions of the purpose of the particular tutorial discussed, the role of work that was completed in preparation for the tutorial, and the role of the student and the tutor in this particular tutorial. These dimensions are included in explanations of the categories below.

\section{Tutorials as a place where tutors help students to develop an understanding of concepts}

Tutors' accounts consistent with this category described the purpose of tutorials as being to help students to understand the concepts involved in the topic they were studying and to help the students to see the topic in the way that the tutors did themselves. (It should be noted that the words 'topic' and 'material' are used generically in this paper to denote the body of knowledge that is the focus of a particular tutorial). The role of students' preparation work was for the tutor to assess the students' current level of understanding. Under this category, tutors' described their role in the tutorial in terms of steering the student towards what they were expected to know. They described the role of the students in terms of engaging with the topic by asking and answering questions and admitting to the tutor what they did not understand.

The primary purpose [of the preparation work] is just trying to get a gauge on where we should focus in respect of the tutorial. [My role is] getting them to think about those issues, obviously gauging what they are understanding and think about it in a different way to elevate their understanding... [I do this in] quite a straight forward way actually in terms of just asking a series 
of questions... and from the answers they'll give, I will then ask them another question which should explore it in that way. So in a crude sort of way, I guess actually you could say it is more like a quiz, to kind of tease apart their understanding and encourage them by asking themselves questions, and in particular, answer the questions that I'm asking to clarify issues... But in terms of their role, to be quite honest, I am expecting them to come along with motivation, enthusiasm and for them to get to grips with the actual material and to engage with it.

(T13: Medical Sciences)

Sometimes people would give me good information and I would say 'OK, yes, but do you understand why that's so?' and we would go through it. Hopefully they would go 'aah, I see it now' and I think that's what my role is in the tutorial, is to steer them towards what they are expected to know and help them with what they are expected to understand... The purpose [of tutorials] isn't to make sure they can answer that question; it is to get them thinking about that area of the work. Again, the concept is to straighten their minds so that if they're asked a different question, they can apply what they know.

(T14: Mathematical and Physical Sciences). 


\section{Tutorials as a place where students see how to approach their discipline}

Tutors' accounts consistent with this category described the purpose of tutorials as being for the student to develop their thinking within the subject. They described the role of the preparation work as being for the student to think about a part of the discipline. They described their role as tutors in terms of demonstrating how a member of the discipline would approach the particular topic, whilst the role of the students was to identify problem areas and to participate in overcoming these in a way a member of the discipline would.

The qualitative difference between categories 1 and 2 was the disciplinary focus in category 2. Whereas in category 1 , tutors described seeking to steer students towards what they are expected to know, in category 2 what students were expected to know was clearly located within the discipline, and the tutor's role was more to demonstrate how those within the discipline would approach the particular topic rather than helping them to understand particular concepts directly.

[I give students essays] partly because I think its fair to say that you cannot produce an essay without having read the material and its partly the need for them to learn how to write scientific essays... I think the most important [role of the tutor] is teaching the student how to think... I think it's largely done by example and that's one of the advantages of getting them to ask questions is that you can then, if you like, demonstrate how to approach answering that question. Which is why I say it's useful to be able to turn the question back on them and see how well they approach it. I think it is quite effective because, remember, I have no knowledge of what questions they will ask so they know I'm answering it cold. I do try to set out the logical progression of how I get to the answer rather than just saying 'the answer is $\mathrm{x}$ '.

(T3: Life and Environmental Sciences). 
[Their preparation work has] led them to redevelop most of the main ideas and, if luck will have it, many of those ideas have been covered in lectures beforehand anyway, so they cover the lectures and they're reading. The harder, more interesting things you do in the tutorials ... Primarily you try to show them strategies for solving a problem, strategies an experienced [member of the discipline] would bring to bear and you illustrate and I guess you also show humility in a way: 'Don't be frightened if you don't solve it the first time, the connections might be made later'.

(T10: Mathematical and Physical Sciences).

\section{Tutorials as a place where evidence is critically discussed}

Tutors' accounts consistent with this category described the purpose of tutorials as being to develop students' critical thinking about the discipline. They described the role of preparation work in terms of the student beginning to think critically about the issues that would be discussed in the tutorial. They described their role in the tutorial as being to relate the students' ideas to a wider context, whereas the students' role was to present and critically discuss the evidence. They indicated that they were not always successful in getting students to fully take on this role, as is suggested in the quote from tutor T12 below, but they clearly indicated that it was part of the role they expected students to take in the tutorial.

The qualitative difference between categories 2 and 3 was the focus on the students thinking critically about the topic under discussion in the tutorial. In categories 1 and 2, the focus was on how the tutor helps the student to understand the topic, whereas the focus in category 3 was on the students developing a critical understanding of the topic.

The purpose of my firstly giving them essays is to ensure that they come up with not only having read things, but having thought about what they can do with the things they have read... I think 
that's really it, to make them think critically about what they've read and try and put it into some kind of framework, otherwise it's just a series of 5-10 things they've read... [My role was to act] as a sheep dog. I kind of herded them in and I think a sheep dog is quite a good analogy, rather than a shepherd, as I don't feel I had specific things that I wanted to get through ... Their role is really to be able to communicate what they've read, I ask them to summarise what are the three key points they have made in their essay ... Another role that I'm keen to get students to fulfil in tutorials is to be critical of what they've read and I spend a long time in many tutorials trying to get people to criticise what they've read and that can be quite hard going.

(T12: Life and Environmental Sciences)

[My role is] number one to listen, obviously to correct inaccuracies, that's what we're there for. Mainly to provide a sounding board for their ideas and to put their ideas into a wider context ... [Their role involves] presenting the evidence, discussing the evidence, using the tutor to answer things they haven't understood or that they want to qualify, and having an occasion where they can practice putting their own point of view ... The essay has the function of trying to get out a large amount of different information to produce a synthesis, such that they can see what the major problems are, how it should be approached, ones to which there are answers, ones to which there are not answers, ones which need looking at and how you can look at them.

(T5: Medical Sciences)

\section{Tutorials as a place where new positions on the topic are developed and refined}

Tutors' accounts consistent with this category described the purpose of tutorials as being to develop and refine new positions on the topic being discussed. The role of the preparation work was for the students to develop an initial position on the topic. In this category, tutors described their role in terms of providing a context in which students could develop this initial position, and the role of the student was to develop a new, yet still provisional, position. 
The qualitative difference between categories 3 and 4 was that in category 4 , the tutors focused on students developing and refining their own positions on the topic being discussed as well as thinking critically about established positions on the topic, as was the case in category 3. Perhaps unsurprisingly, tutors describing tutorials in ways that were consistent with category 4, also described students coming up with ideas that were new to them more frequently than under the other categories. There was also an increased sense that what was developed in the tutorial was provisional and would be reviewed and developed as the students continued their studies.

In the tutorial I try to facilitate the discussion and fade into the background as much as I can, again it's one of those things that depends on the students but I normally try to fade into the background and facilitate something, to give it a purpose and this is what we are thinking about. I bring the conversation back on course if it strays too far away from the basic structure... [the students] have to speak out and assume some kind of responsibility for contributing to the discussion and they get to think out loud and they get to interact with another opinion, take that opinion, think about it and come up with an original response ... In this particular context, the main role of tutorials is for students to be able to express themselves in a particular way, to be able to introduce their own thoughts on the subject and be able to interact with other students. As a student, you get an opportunity to contribute something of your own to the subject.

(T7: Social Sciences).

I think predominantly [my role is] to bring people out of themselves and allow them to experiment with ideas... [Their role is] to come along, certainly, with an agenda with some kind of trajectory through what they'd been reading and, ideally, to come along with some questions. Again to embrace the sense of provisionality, to say 'I'm happy with this idea but I'm still not happy how 
these two things connect. What do you think of them?' Not even to look for the answer but to look at another view and, yes, to come along with that sense of something being consolidated. 'I've done some reading, I've looked at some areas and I have a sense of what's going on but also things are still provisional'. I always talk about the etymology of an 'essay' being 'to essai', to try and not to prove or to accomplish, but simply to try to tie something together in one way and I would like the students to leave with a sense that they would write a different essay, not just in the light of what I might have said but also what the others might have said.

(T 6: Humanities).

\section{Relations between the categories}

The qualitatively different descriptions can be logically related to each other in terms of a referential (meaning) aspect and a structural aspect. The referential aspect characterizes the categories in terms of what the tutorials described mean. In this case the referential aspect is differentiated in terms of whether tutorials are seen as being about engagement, critical engagement, or the development of new positions. The structural aspect characterizes the categories in terms of what is in the foreground and background in each category. In this case, the structural aspect is differentiated according to whether concepts or the discipline are fore-grounded in each category. Table 1 summarises the referential and structural aspects of each of categories of description.

\section{TABLE 1 ABOUT HERE}

The referential and structural aspects form an inclusive hierarchy with each new category subsuming and building on the previous aspect and in this way the four categories form an inclusive and expanding hierarchy. Thus category 4 includes categories 1 to 3 but category 1 
does not include any of the other categories. However, it should be noted that the outcome space does not represent a developmental hierarchy as claimed by Webb (1997), in that there is no suggestion that academics necessarily move through the different categories of tutorials as they learn more about tutoring. Rather it is argued that tutors' experiences of tutorials change according to their perception of the learning and teaching environment and their perceptions of the nature of the subject taught.

\section{Relations between tutors' accounts of tutorials and their perceptions of the teaching and}

\section{learning environment}

The four ways of describing tutorials outlined above show a shift from category 1, which focuses on the tutor helping the students to understand concepts, to category 4 , which focuses on students developing new positions within the discipline being discussed. The four categories do not represent an unchanging style that tutors use to approach tutorials but rather, as with approaches to teaching (Prosser \& Trigwell 1999), appeared to be related to their perceptions of the situation in which they were tutoring.

Obviously, with only 20 tutors in the sample, caution is required when reporting these relations. However, that said, a number of factors appeared to be related to the highest category of tutorials that was consistent with tutors' accounts of tutorials. As is shown in Table 2, there appeared to be some relation between disciplines and the categories of tutorials that tutors expressed in their interview. The tutors who appeared to express experiencing tutorials in a way that was congruent with category 1 were all from science-based disciplines, whilst the tutors who experienced tutorials in a way that was congruent with category 4 were 
from disciplines within the humanities and social sciences. However, there was also variation within disciplines with tutors from the same discipline describing tutorials in qualitatively different ways (i.e. in ways consistent with different categories) in 6 out of 10 of the disciplines. In three disciplines, there was a difference of two categories between the tutors' accounts' of tutorials.

\section{TABLE 2 ABOUT HERE}

There appeared to be no relation between tutors' levels of tutoring experience and the ways in which they described tutorials, and no relation between tutors' sex and the higher category consistent with their accounts of tutorials.

There was some limited qualitative evidence of a link between tutors' perceptions of the teaching context and their account of tutorials. Where tutors felt a large amount of content needed to be covered within the tutorial, where tutors perceived this material to be complex, and where the tutorial was in close proximity to an examination on the topic, tutors tended to describe tutorials in ways which were consistent with the lower categories of ways of describing tutorials. For example, T7 mentioned another course that T7 taught, in which some of these factors affected the approach that was taken in the tutorials. By way of contrast some of T7's quotes cited above (under category 4) are included:

In this particular context, the main role of tutorials is for students to be able to express themselves in a particular way to be able to introduce their own thoughts on the subject and be able to interact with other students. As a student, you get an opportunity to contribute something of your own to 
the subject. ... [With this other course] they have to do well in the examinations. This is one constraint. The structure of the course, it's about coverage. You have to cover a hell of a lot. That is a constraint. I still try to do a similar thing but there are differences. There is more of an issue that they understand detail... I have to be more goal orientated. I know that there are five substantial points that they have to emerge with: a), b), c) d) e). It has huge coverage and they are examined on it.

(T7: Social Sciences)

\section{Relations between tutors' accounts of tutorials and their approaches to teaching}

There appeared to be a relation between tutors' accounts of tutorials and their approaches to teaching as measured by the ATI.

\section{TABLE 3 ABOUT HERE}

Table 3 shows that as the highest category consistent with a tutor's account increased, so their ITTF approach score fell and their CCSF approach score increased. This suggests that, for this small sample of tutors, the higher the category of ways of describing tutorials that was consistent with their account, the more likely they were to focus on student learning and the less likely they were to focus on their role in terms of information transfer in their approach to teaching that particular tutorial.

\section{Discussion}

This study constituted variation in the ways that tutors describe tutorials. Tutors' accounts of tutorials ranged from tutors describing tutorials as a place where they help students to develop an understanding of concepts to tutors describing tutorials as a place where new 
positions on the topic are developed and refined. The highest category of ways of describing tutorials consistent with a tutor's account of tutorials appeared to be related to their discipline, and their approaches to teaching. There was also evidence that suggested a relation between their accounts of tutorials and their perceptions of their teaching and learning environment. Finally, there was evidence of a relation between the highest category of tutorials that tutors expressed and their approaches to teaching those tutorials. The higher the category of ways of describing tutorials that tutors accounts were consistent with, the higher their conceptual change/student-focused score and the lower their information transfer/ teacher-focused score on the ATI.

So what does this tell us about academics' approaches to particular teaching methods more generally? Despite the apparently favourable conditions (tutor autonomy in what and how to teach, small class sizes, in an environment where teaching is valued) offered by tutorials at Oxford, there was still qualitative variation in the ways these academics talked about tutorials. Whilst these differences appeared to be related to academics' disciplines, there were also differences within disciplines. These differences seem to suggest that, in line with Prosser \& Trigwell (1999), and Prosser et al (2003) it is academics' perceptions of their teaching environment, rather than the environment per se, that appeared to influence how they approached their teaching.

This finding has two important implications for the way in which university academics are supported in improving their teaching. First, the finding that academics appear to have qualitatively different accounts of a single teaching method suggests that academic 
development which focuses on helping academics to increase their repertoire of teaching methods (which Gibbs \& Coffey 2000 and Coffey \& Gibbs 2002 report is a goal of many training programmes for university teachers throughout the world) without examining their ways of accounting for their teaching are unlikely to be highly effective. This is because this study provides evidence that different academics approach similar teaching methods differently depending on the ways in which they think about those teaching methods. Thus, it seems plausible that academics re-interpret different teaching methods according to their ways of thinking about teaching and learning.

Second, this study constituted variation in academics' accounts of one particular teaching method, tutorials at the University of Oxford. There were also relations between these academics' accounts of this teaching method and their approaches to teaching. Given there is evidence in other contexts of a link between academics' approaches to teaching and the quality of their students' learning (Trigwell et al 1999, Prosser et al 2003), this provides some limited evidence that helping academics to develop more sophisticated ways of thinking about particular teaching tasks may be a way to support them in improving the learning of their students.

However, as the first to examine academics' accounts of a particular teaching method, this study had a number of potential limitations. First, although the sample was selected to be large enough to maximise the variation in academics' accounts of tutorials, it was not selected in a way that makes the results generalisable. Nevertheless, the relation between academics' accounts of tutorials and their approaches to teaching, does offer some support 
for the validity of the categories constituted because the approaches to teaching inventory has been found to be reliable in a number of contexts and amongst large numbers of university academics (Prosser and Trigwell 1999, p.156, Prosser et al 2003).

Another potential limitation of this study was the cross-disciplinary focus on tutorials that was taken. The finding that academics who experienced tutorials in a way that is congruent with category 1 were all from science-based disciplines, whilst those who experienced tutorials in line with category 4 were from the social sciences and humanities, raises the question of whether it is possible to treat 'tutorials' as a single entity across different disciplines. There are two responses to this. The first is that, as indicated in Table 2, there was variation across broad discipline areas in a way that suggested there was an overlap between tutorials in different disciplines. The second response is that this is an area that is suitable as subject for further research, which could offer a deeper insight into the meaning of tutorials in different disciplines.

To return to the Oxford context, this study has suggested that there is qualitative variation in the ways that academics account for tutorials at Oxford. The variation in academics' accounts of tutorials appeared to be related to their approaches to teaching, which in other contexts have been found to relate to the quality of students' learning. This suggests that, even within a teaching and learning environment that many would consider to be ideal, unless academics are focused on the learning of their students rather than their own performance, their teaching may act as a barrier to high quality student learning. 


\section{Acknowledgements}

I would like to thank Keith Trigwell for his contribution to this paper in terms of his involvement in verifying the analysis of the interviews and discussing the ideas contained in

the paper. I would also like to thank participants at the $11^{\text {th }}$ Improving Student Learning Symposium (Theory, Research and Scholarship - 10 Years On), Paul Trowler, and the anonymous referees, for their very helpful comments on earlier drafts of this paper.

\section{References:}

Åkerlind, G.S (2005). 'Variation and commonality in phenomenographic research methods', Higher Education Research \& Development, 24, 321-334.

Åkerlind, G.S. (2003). Growing and developing as a university teacher - variation in meaning. Studies in Higher Education, 28, 375-390.

Ashwin, P. (2005). Variation in students' experiences of the Oxford Tutorial, Higher Education 50, $631-644$.

Coffey, M. \& Gibbs, G. (2002) Measuring teachers' repertoire of teaching methods. Assessment \& Evaluation in Higher Education, 27, 383 - 390.

Commission of Inquiry (1997). Commission of Inquiry Report. Oxford, University of Oxford. 
Gibbs, G. \& Coffey, M. (2000) Training to teach in higher education: a research agenda. Teacher Development, 4, 31-44.

Gow, L. \& Kember, D. (1993). Conceptions of teaching and their relation to student learning. British Journal of Educational Psychology, 31, 93-97.

McCune, V. (2004). Development of first-year students' conceptions of essay writing. Higher Education 47, 257-282.

Martin, E. \& Balla, M. (1991) Conceptions of teaching and implications for learning. Research and Development in Higher Education, 13, 298 - 304.

Marton, F. \& Booth, S. (1997). Learning and Awareness. New Jersey, Lawrence Erlbaum Associates.

Moore, W.G. (1968). The Tutorial System and Its Future. Oxford, Pergamon Press.

Palfreyman, D. (Ed) (2001). The Oxford Tutorial: 'Thanks, you taught me how to think'. Oxford: Oxford Centre for Higher Education Policy Studies.

Prosser, M. \& Trigwell, K. (1997). Relations between perceptions of the teaching and environment and approaches to teaching. British Journal of Educational Psychology, 67, 2535. 
Prosser, M. \& Trigwell, K. (1999). Understanding Learning and Teaching: The experience in higher education. Buckingham: Society for Research into Higher Education and Open University Press.

Richardson, J. (1997). The concepts and methods of phenomenographic research. Review of Educational Research, 69, 53-82.

Säljö, R. (1997). Talk as data and practice - a critical look at phenomenographic inquiry and the appeal to experience. Higher Education Research \& Development, 16, 173 - 190.

Samuelowicz, K. \& Bain, J. (1992). Conceptions of teaching held by academic teachers. Higher Education, 24, 93-112.

Shale, S. (2001). The Oxford tutorial in the context of theory on student learning. In D. Palfreyman (Ed) The Oxford Tutorial: 'Thanks, you taught me how to think'. Oxford: Oxford Centre for Higher Education Policy Studies.

Tapper, E. \& Palfreyman, D. (2000). Oxford and the Decline of the Collegiate Tradition. London: Woburn Press.

Trigwell, K. \& Prosser, M. (1996). Changing approaches to teaching: a relational perspective. Studies in Higher Education, 21, 275-284. 
Trigwell, K., Prosser, M., \& Waterhouse, F. (1999). Relations between teachers' approaches to teaching and students' approaches to learning. Higher Education 37, 55-70.

Trowler, P. \& Turner, G. (2002). Exploring the hermeneutic foundations of university life: deaf academics in a hybrid 'community of practice'. Higher Education 43, 227-256.

Universities Grant Committee (UGC) (1964) Report of the Committee on University Teaching Methods (The Hale Report), London: HMSO.

Webb, G. (1997). Deconstructing deep and surface: towards a critique of phenomenography. Higher Education, 33, 195-212. 
Tables

\begin{tabular}{clll}
\hline & \multicolumn{3}{c}{ Referential Aspects } \\
\cline { 2 - 4 } $\begin{array}{c}\text { Structural } \\
\text { Aspects }\end{array}$ & Engagement & Critical Engagement & $\begin{array}{l}\text { Development of New } \\
\text { Positions }\end{array}$ \\
\hline Concepts & 1 & 3 & 4 \\
Discipline & 2 & 3 &
\end{tabular}

Table 1: The referential and structural aspects of the categories of ways of describing tutorials

\begin{tabular}{ccc}
\hline & \multicolumn{2}{c}{ Broad Discipline Area } \\
\cline { 2 - 3 } Category of Description & $\begin{array}{c}\text { Humanities \& Social } \\
\text { Sciences }\end{array}$ & Sciences \\
\hline 1 & 0 & 4 \\
2 & 1 & 3 \\
3 & 2 & 5 \\
4 & 5 & 0 \\
\hline
\end{tabular}

Table 2: Tutors' broad discipline area by the highest category of ways of describing tutorials they expressed in their interview 


\begin{tabular}{rrcc}
\hline Category of Description & & $\begin{array}{c}\text { Information Transmission/ } \\
\text { Teacher Focused Scale }\end{array}$ & $\begin{array}{c}\text { Conceptual Change/ } \\
\text { Student Focused Scale }\end{array}$ \\
\hline 1 & Mean & 3.22 & 3.66 \\
& $\mathrm{~N}$ & 4 & 4 \\
& Std. Deviation & 0.78 & 0.67 \\
\hline 2 & Mean & 2.97 & 3.69 \\
& $\mathrm{~N}$ & 4 & 4 \\
& Std. Deviation & 0.72 & 0.47 \\
\hline 3 & Mean & 2.34 & 3.91 \\
& $\mathrm{~N}$ & 6 & 6 \\
& Std. Deviation & 0.42 & 0.56 \\
\hline 4 & Mean & 2.14 & 4.50 \\
& $\mathrm{~N}$ & 4 & 4 \\
& Std. Deviation & 0.43 & 0.31 \\
\hline Total & Mean & 2.63 & 3.94 \\
& $\mathrm{~N}$ & 18 & 18 \\
& Std. Deviation & 0.69 & 0.58 \\
\hline
\end{tabular}

Table 3: Means of tutors' scores on the two approaches to teaching inventory scales organised by the highest category of ways of describing tutorials they expressed in their interview

Total Length of Manuscript: 6990 words 